\title{
Cómo Formar a los Periodistas
}

\author{
How To Train Journalists
}

Juan Pablo Cárdenas Squella *

Especialista en Periodismo

Instituto de Comunicación e Imagen

Ignacio Carrera Pinto 1045 Santiago

Universidad de Chile

cardenas@uchile.cl

Recibido: 3 de agosto, 2007. Aceptado: 20 de agosto, 2007

Resumen: La formación de los periodistas difiere mucho entre las múltiples universidades del país. La malla curricular, además, ha sufrido constantes modificaciones desde que se fundara la primera Escuela de Periodismo hace más de 50 años. ¿En qué poner el acento? ¿En la formación de las destrezas técnicas o en la formación de un periodista culto, conciente de su responsabilidad ética y educacional?

Palabras clave: periodismo, educación, escuelas, ética, objetividad, honestidad.

Abstract: Journalists' education is very different from one university to another in Chile. Also, the curricular planning has suffered many changes since the first Journalist School was founded 50 years ago. What should be emphasized? Educating journalists in their technical skills or developing educated journalists and conscious about their ethical and educational responsibilities?

Key words: Journalism, education, universities, ethics, objectivity, honesty.

\section{INTRODUCCIÓN}

Desde que se fundaron las primeras escuelas de periodismo se discute respecto de su sentido y orientación. Con su creación se asumía la necesidad de formar profesionales capaces de mejorar el nivel de la profesión y enfrentar los nuevos desafíos que el progreso científico y tecnológico le imponía a la comunicación masiva, especialmente con la irrupción de la radio y, luego, la televisión.

Se formuló entonces la idea de darles un buen barniz cultural a los nuevos periodistas. Los profesores nos instaban a 'ser un océano de cultura con un centímetro de profundidad'. De allí que los primeros programas de estudios le dieran tanta importancia a los cursos introductorios. Se trataba de que en

\footnotetext{
* Premio Nacional de Periodismo 2005. Profesor titular del Instituto de Comunicación e Imagen, Facultad de Ciencias Sociales, Universidad de Chile.
} 
poco tiempo aprendiéramos algo de historia, economía, sociología y relaciones internacionales. Se propiciaron, además, una cantidad de cursos destinados a apreciar el arte, conocer nuestro sistema institucional y los aportes del desarrollo científico. Desde el comienzo, se le asignó importancia a los cursos de publicidad y relaciones públicas apostando a un campo ocupacional que tendía a desarrollarse notablemente. Los nuevos periodistas tendríamos, también, que redactar bien, hablar con soltura e, incluso, vestir tan adecuadamente como los abogados para encarar nuestra actividad y dignificarla.

Lo cierto es que en los años de universidad conocimos más científicos sociales, filósofos y artistas que periodistas. Quienes ejercían la profesión, en un buen número y por mucho tiempo, desconfiarían de las escuelas de periodismo. "Esta es una actividad que se aprende más en los talleres, incluso en la bohemia, más que en las universidades", se nos espetaba. Y en todo el mundo, y en especial en América Latina, se empezó a distinguir entre periodistas empíricos o universitarios, es decir, formados en las redacciones de los periódicos o en la cátedra. En rigor, se pensaba entonces que los editores de los medios seguirían siendo los mejores maestros, con el derecho de humillarnos hasta la grosería cuando no hacíamos bien las cosas. ¡Vaya con qué epítetos destrozaban nuestras primeras carillas para arrojarlas luego en el cesto de la basura con una puntería que me sorprende hasta hoy! Pero la renuencia de muchos periodistas para oficiar de profesores universitarios favoreció, en definitiva, que sólo se avinieran a esta posibilidad los más lúcidos y progresistas. Así es como tuvimos la oportunidad de intimar con profesores de la talla de Mario Planet, Hernández Parker, Andrés Sabella y otros mitos vivientes, cuya experiencia, cultura y sencillez superó largamente su inexperiencia pedagógica.

A decir verdad, las primeras escuelas se preocuparon bastante de infundirnos valores y un sentido misional. Sacerdotes, filósofos y periodistas reconocidos por su solvencia ética y prestigio nos hablaron de la falacia de la 'objetividad' patrocinada por los primeros manuales de periodismo estadounidenses. Nos convencieron de que en esta profesión nunca ganaríamos dinero y que la vocación cuando mejor se probaba era en los tiempos difíciles, es decir, en la dictadura y en la guerra. Nos dieron luces, además, sobre nuestra incompatibilidad esencial con los políticos y el poder, la necesidad de desconfiar hasta de las instituciones más veneradas, tanto como de los propios medios informativos. Todo lo cual pudimos probar bajo el oscurantismo de la Dictadura Militar y lo que le siguió. En el salto brutal de nuestro país de la modernidad al post modernismo. Desde la época en que gravitaban espesamente ideologías a la realidad actual regida por el exitismo personal. 


\section{CAMBIOS EN LA MALLA CURRICULAR}

Con la reforma universitaria de fines de los 60, los estudiantes nos cuestionamos también nuestra formación tan general y las escuelas dieron un razonable giro hacia una formación más práctica. Las cátedras de Estética, de Historia Nacional y Universal tuvieron que ceder horas de clase a los nuevos ramos de fotografía, radio y televisión. Las mallas curriculares se propusieron adiestrarnos para realizar buenos libretos radiales y televisivos, aunque en estos cambios tuvimos que soportar profesores tan pedantes que se burlaban de las reglas gramaticales, como de la necesidad de distinguir el sujeto y predicado de una oración. En la coloquialidad propiciada por algunos de ellos (escritores jóvenes e irreverentes, por supuesto) quien se burlara más de las normas de puntuación o pusiera más garabatos en un texto, corrientemente, se ganaba la mejor nota. En lo relativo a la formación ética, no obstante, se mantuvo preocupación por infundirle a los nuevos periodistas consonancia con la honestidad para enfrentar los acontecimientos que debíamos convertir en noticia, sin embargo, poco a poco se empezó a asentir con el periodismo militante y la legitimidad de un ejercicio profesional partidista y sectario. Las propias escuelas de periodismo fueron alineándose con las posiciones irreconciliables de la política y de la Guerra Fría, hasta que vino el Quiebre Institucional de 1973, donde la exacerbación de los ánimos transmitidos por la prensa derrumbó nuestra República, la libertad y el sentido crítico de nuestras universidades.

De allí en adelante, las carreras de periodismo derivaron en entidades asépticas, destinadas a formar reporteros mecánicos cuyos mandamientos fueran la pirámide invertida y las interrogantes del periodismo definidas por aquellos manuales de estilo de los grandes periódicos y agencias informativas. Los nuevos periodistas debían prepararse para asistir a las conferencias de prensa, registrar sin cuestionarse lo que se les decía que pasaba y, por cierto, aprender a transmitir las noticias sin implicarse o conmoverse para nada con los más terribles episodios de la realidad. Desde entonces es que se identifica tanto nuestro quehacer con el de los relacionadores públicos, por lo que una gran cantidad de periodistas languidece como voceros, correctores y porta documentos de los políticos, empresarios y otros que deben cuidar su imagen personal o corporativa. De paso digamos que la grabadora se consolidó como el recurso fundamental del ejercicio profesional, de tal forma que el micrófono es todavía el fálico distintivo de nuestro quehacer, así como antes lo fueron las máquinas de escribir.

Por varias décadas lo que ha preocupado a las escuelas de periodismo es desarrollar destrezas técnicas entre los estudiantes. Se redujeron al extremo 
las clases destinadas a la formación integral. Los controles de actualidad constituyen todavía el método más recurrido para que los futuros periodistas aprendan algo de política, economía, arte, deporte y espectáculos. En el propósito, además, que identifiquen a las autoridades, ubiquen a los países en el mapa y reconozcan, por ejemplo, las jerarquías castrenses, todavía tan presentes en la noticias nacionales. Los profesores más antiguos y, tal vez, más críticos nos quejamos hasta hoy de la escasa disciplina de los futuros periodistas en la lectura, de su pobrísimo maletín literario e incluso de su desprecio por la prensa de papel. Cuando indagamos sobre las fuentes de conocimiento que tienen los estudiantes quienes se inician en el ejercicio profesional concluimos que los noticiarios de televisión y los portales electrónicos de los grandes diarios son su principal derrotero. Lo que es, sin duda, francamente pavoroso en un país en que la televisión abierta se ha vulgarizado a extremos tales que poco o, más bien, nada aportan al derecho humano de comprender y transformar el mundo, condición indispensable para el ejercicio de la soberanía popular y la profundización de la democracia.

Hay más de sesenta escuelas de periodismo de norte a sur del país, algunas de las cuales casi únicamente tienen profesores hora y el pizarrón sigue siendo el recurso pedagógico principal. Carreras que reclutan docentes entre los periodistas más 'exitosos' y renombrados de la TV, lo que les sirve para venderse en el mercado, ganar puntos en la competencia por obtener alumnos, ojalá $A B C 1$, que paguen rigurosamente y no se cuestionen mucho la vida. En una evaluación realizada a una escuela de periodismo en Antofagasta, pude comprobar el pobrísimo nivel de sus docentes a través de los flagrantes errores teóricos y de ortografía que evidenciaban sus apuntes de clases. Siempre recuerdo que al término de la Dictadura, el Decano de Ciencias Sociales de la Universidad de Chile me invitó a reanudar mi actividad docente en "una Escuela en que el nivel de los alumnos era superior al de sus profesores".

Hay otras escuelas en que el desplazamiento técnico es envidiable. En que los alumnos se la pasan con cámaras, talleres de radio y otros recursos sin que sus profesores manifiesten el mínimo interés por su formación cultural y ética. Establecimientos que quieren ganar puntos con niñas bien dotadas físicamente que luego sean reclutadas por los canales y la farándula comunicacional. Muchachos que son adiestrados para transmitir de fútbol y que difícilmente como periodistas deportivos se muestran siquiera capaces, después, de distinguir las manifestaciones olímpicas y tantas otras disciplinas físicas incorporadas al quehacer deportivo y las competencias mundiales.

Hay que reconocer que en la Dictadura e, incluso, en la Transición hay excepciones importantes al diagnóstico anterior. Escuelas de periodismo que 
procuraron siempre compatibilizar la capacitación técnica con la formación cultural y ética. Con todo, éstas se observaron sesgadas en lo ideológico, extremadamente confesionales y poco tolerantes, con lo cual muchos maestros y alumnos tuvieron que someterse a la censura y la autocensura, práctica que hasta hoy marca tanto el desempeño profesional. Al mismo tiempo que a los estudiantes se les prohibió organizarse en centros de alumnos y federaciones, se los desincentivaba para integrar el Colegio de Periodistas y toda forma de organización gremial o sindical. De allí que pocos profesionales en Chile sean tan competitivos y reacios a formar asociaciones que velen por el respeto a su dignidad laboral.

\section{DIFERENCIAS PROFUNDAS}

La situación actual de las escuelas de periodismo difiere mucho caso a caso. Existen algunas que han corregido notablemente sus programas de estudio y recuperado sus propósitos de impartir una formación que le entregue a la sociedad un periodista tan sólido en conocimientos, como en valores y destrezas. Escuelas que manifiestan tanto interés por ofrecer infraestructura, equipos y talleres como por enriquecer sus bibliotecas, actividades de reflexión y extensión e, incluso, desarrollar especialización y post grado. El Programa de Libertad de Expresión del Instituto de Comunicación e Imagen de la Universidad de Chile es uno de los aportes más encomiables al desarrollo de un periodismo libre y que desde las propias aulas vigila la dramática realidad de la comunicación social en nuestro país. Dramáticamente marcada, como se sabe, por la falta de diversidad y el sometimiento a las directrices definidas por los avisadores y los poderes fácticos.

Pero lo que prevalece es un número absurdo de escuelas de periodismo de pésimo nivel y funcionales al negocio de la educación superior. Escuelas de bajo costo operacional, que compiten por la matrícula pagada y sin posibilidad y disposición alguna de someterse a cualquier calificación o supervisión académica. Organizaciones que entregan, sin embargo, la mayor cantidad de títulos y grados en el periodismo chileno y que han llegado al descaro de organizar programas de rápido trámite, livianísima cobertura curricular y que lanzan al mercado cantidades de ineptos como tantas veces podemos comprobar en los medios informativos. Reporteros que apenas sirven para sostener micrófonos o como anda, coge y trae comunicados de prensa que llenan los noticiarios; a quienes se les puede pagar muy poco, valiéndose de la necesidad de realizar prácticas profesionales para obtener sus títulos, y despedir sin miramiento alguno de las leyes laborales. 


\section{Y AHORA, ¿QUÉ?}

Han transcurrido más de 50 años desde que se fundara la primera escuela de periodismo y lo cierto es que la situación es de dulce y agraz. Por un lado, los egresados lograron demostrar que era necesario que esta actividad tuviera sitio como disciplina universitaria. Más allá de los todavía emblemáticos periodistas empíricos, varias generaciones universitarias justificaron su paso por la universidad por la solvencia ética demostrada para desafiar la censura y llevar la noticia a un país paralogizado por la represión. Los egresados universitarios son, asimismo, los que han podido cultivar con mejor talento el Periodismo Interpretativo (el que explica la noticia), como el de Opinión (que consolida postura y compromiso con el acontecer). Sin duda, los dos géneros del periodismo que exigen mayor formación general, metodología y, ahora, nivel de especialización. Objetivos a los cuales el paso por la universidad puede contribuir y formar hábito mejor que el estrés y la vorágine de las redacciones de los medios. El reportaje, el informe especial, la columna y el ensayo periodístico exigen de cultores bien informados, eficientes en la capacidad de comunicar y, por supuesto, rigurosos, libres y honestos. Rebeldes, incluso, a las pautas digitadas por sus editores. La propia labor del periodismo informativo se ha de enriquecer por la acción de reporteros más cultos y metódicos, cuando se demuestran capaces de relacionar los hechos y darle valor agregado a sus despachos considerando que las noticias de la política, la economía, la religión, las relaciones internacionales, el desarrollo científico y tecnológico, el deporte, la educación, el arte y la vida social necesariamente se interrelacionan y se explican unas con otras en la globalización del mundo y la preservación de las idiosincrasias de cada cultura.

Es imprescindible, sin embargo, hacer algo para detener la titulación masiva de periodistas y el descaro tan generalizado de escuelas de precario nivel y que en el afán de lucrar cometen despropósitos que se constituyen en una burla para sus educandos y la misión social del periodismo. Es necesario que las propias universidades velen por sus planes de estudio, por el nivel de sus docentes y la calidad de sus instalaciones. Es preciso, además, que el Estado, su institucionalidad educacional, el Colegio de Periodistas y, de ser posible, la comunidad, intervengan, frenen la proliferación de escuelas deficitarias, clausuren establecimientos o exijan su calificación. La autonomía universitaria no puede presentarse como excusa para tolerar el engaño o la estafa educacional, sobre todo cuando ha quedado de manifiesto que, en este caso, el mercado no regula nada o, más bien fomenta o favorece el progresivo empobrecimiento de una actividad fundamental en la conciencia y formación de los pueblos y, por ende, de su progreso. 
Prácticamente todas las carreras universitarias se cuestionan sus programas de estudio, su sentido y los cambios que necesariamente hay que implementar. ¿Será necesario estudiar tantos años de Medicina para ejercer después en labores tan específicas o auxiliares? ¿No pasa lo mismo con el Derecho y los abogados? ¿No sería mejor reconocer la multiplicidad de funciones y generar distintas carreras como en un momento se decidió con la Odontología como, asimismo, las carreras que se han derivado de la Agronomía? ¿No ocurre algo similar con el periodismo? ¿No es público y notorio que bajo el distintivo de periodista se ejercen actividades tan diversas y a través de medios de comunicación tan diversos como la radio, la televisión, los periódicos escritos y los diarios electrónicos?

Soy de los que piensa que el periodista es uno solo y que su competencia debe desafiar los distintos estilos que exigen los distintos medios. Jamás aceptaré que un periodista radial no sepa escribir o que en la televisión lo que más importa es ahorrar palabras e ideas en beneficio de la imagen y el rating. El oficio de transmitir informaciones, explicar las noticias, desentrañar sus causas y consecuencias debe ejercerse a través de todos los medios al alcance de la sociedad. Al mismo tiempo que el periodismo tiene intención informa, explica u opina- tiene un sentido misional y una enorme responsabilidad ética. Demostrado está que en el mundo actual son los medios los que más contribuyen a enseñar, asumir posiciones y promover actitudes: mucho más que el colegio y la propia universidad. De allí que el autoritarismo siempre busque someter brutalmente a los medios. Por esto que las democracias de mentira proclaman la libertad de expresión, pero en los hechos sutilmente la reprimen con impuestos que gravan e inhiben la lectura, con arreglos publicitarios entre la política, los editores y los avisadores. Con la pasividad con que actúan para evitar la concentración mediática y otras triquiñuelas destinadas finalmente a crear pueblos pasivos, adormecidos en sus derechos e, incluso, engañados por una prosperidad que no es tal o no les toca. ¿En el ejercicio de un periodismo indolente o servil no es que se alimentan los despropósitos contra el medio ambiente, el consumismo febril, la corrupción política y la concentración escandalosa de la riqueza?

Definitivamente, lo que hay que consolidar son escuelas que cumplan con el cometido de formar intelectualmente a los futuros periodistas, entregarles las herramientas para que puedan cuestionar la realidad, servir al progreso humano y hacerlo lo más eficientemente posible. Profesionales comprometidos con la honestidad, más que con la objetividad, término completamente vacuo cuanto se ha probado que un mismo hecho se puede percibir de muchas formas y dependiendo si quien lo observa es joven o anciano, hombre o mujer, católico o musulmán, pobre o rico. En este sentido, pienso que en la 
formación del periodista deben concurrir las ciencias sociales, las artes y los aportes de la biología, la química, la astronomía y todas las ramas científicas que nos permitan explicarnos la vida y el destino humano. Por supuesto que, además, la filosofía y la teología.

Lo que puede quedar para el aprendizaje en talleres son justamente los ramos más frecuentes en las escuelas de periodismo, como la fotografía, la radio y la televisión. Especificidades del ejercicio profesional que en otros países se aprenden en los propios medios, con directores, productores frescos $\mathrm{y}$ adiestrados en las enormes innovaciones que se producen en el campo ocupacional del periodismo. Al respecto, de estas modalidades del periodismo debieran hacerse los cursos generales o introductorios de las escuelas.

Finalmente, en la capacitación de los futuros periodistas es preciso avanzar a la especialización y el post grado. A la formación integral, es necesario agregar la posibilidad de que los periodistas se especialicen en los distintos ámbitos de la actividad que les marque su vocación, interés y posibilidades laborales. Es un lugar común decir que sobran periodistas y que las escuelas debieran reducir o suspender la admisión de alumnos. Ello es cierto pero no tanto si consideramos que hay actividades del periodismo que no pueden ser cubiertas con solvencia por los recién egresados y que, habitualmente, son afrontadas por otro tipo de personas. Me refiero, por ejemplo, a la ausencia de periodistas políticos, económicos o científicos capaces de entender y procurar entendimiento entre los lectores, auditores o telespectadores. Pienso en la lamentable ausencia de críticos literarios, de cine, teatro, artes plásticas y otras manifestaciones creativas. Espacios que en los medios de comunicación son habitualmente cubiertos por artistas, gestores 'culturales' y otros que son parte del sesgado y competitivo mundo de la creación y producción de eventos. Es cuestión de conversar con los editores de medios para comprobar las dificultades que tienen a la hora de asignarle espacios o programas más exigentes a quienes recién ostentan su título de periodista. La crónica periodística que otrora enriqueciera tanto las páginas de redacción hoy tiene poquísimos cultores, justamente porque para hacer esta tarea se necesita saber observar, escribir con estilo y tener idea qué transmitir.

Hay escuelas en Europa que ya resolvieron estos temas impartiendo docencia técnica y especializada sólo a los que ya están licenciados en otras disciplinas, donde se les entrega algo de teoría comunicacional, se les capacita para redactar adecuadamente y se los somete a una disciplina de investigación y reflexión. Otras escuelas prefieren tomar a sus alumnos después de aprobar un bachillerato común para ofrecerles un intenso programa de capacitación en las particularidades de los distintos medios. Existen, sin duda, distintas 